\title{
Effects of quercetin, sitagliptin alone or in combination in testicular toxicity induced by doxorubicin in rats
}

This article was published in the following Dove Press journal: Drug Design, Development and Therapy

\author{
Zheen Aorahman Ahmed (D) \\ Aso Nihad Abtar (iD) \\ Hemn Hassan Othman ${ }^{2}$ \\ Tavga Ahmed Aziz (D) ' \\ 'Department of Pharmacology and \\ Toxicology, College of Pharmacy, University \\ of Sulaimani, Sulaimani, Kurdistan Region, \\ Iraq; ${ }^{2}$ Department of Anatomy and \\ Pathology, College of Veterinary Medicine, \\ University of Sulaimani, Sulaimani, \\ Kurdistan Region, Iraq
}

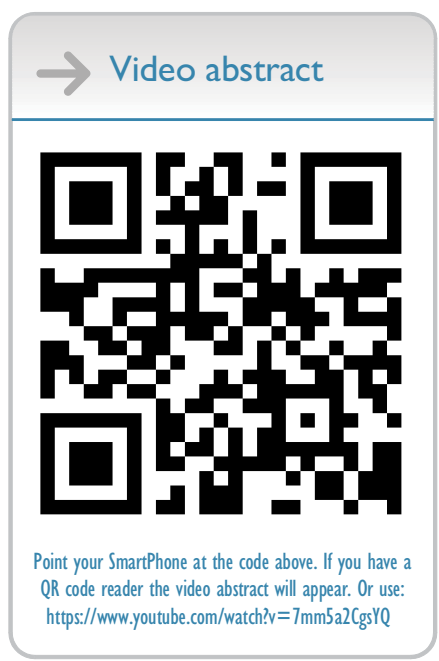

Correspondence: Zheen Aorahman Ahmed; Tavga Ahmed Aziz Department of Pharmacology and Toxicology, College of Pharmacy, University of Sulaimani, Sulaimani,

Kurdistan Region, Iraq

Tel +964 770972 4959;

+964770 I52 3455

Email zheen.ahmed@univsul.edu.iq; tavga.aziz@univsul.edu.iq
Objective: This study aimed to evaluate the effect of quercetin and/or sitagliptin on testicular damage induced by doxorubicin (DOX).

Methodology: Twenty-five male Wistar rats, weighing $240 \pm 20 \mathrm{~g}$, were randomly divided into five groups as follows: a negative control group; that was treated with $1 \mathrm{~mL}$ of $0.9 \%$ sodium chloride; a DOX-treated group received Intraperitoneal (I.P.) DOX injection (3 mg/ $\mathrm{kg}$ ); a group treated with quercetin $80 \mathrm{mg} / \mathrm{kg}+$ sitagliptin $10 \mathrm{mg} / \mathrm{kg}+\mathrm{DOX}$; a group treated with quercetin $80 \mathrm{mg} / \mathrm{kg}+\mathrm{DOX}$; and a group treated with sitagliptin $10 \mathrm{mg} / \mathrm{kg}+$ DOX. All treatment were given orally daily for 21 days with I.P. DOX $3 \mathrm{mg} / \mathrm{kg}$ injection for the treatment groups at days $8,10,12,15,17$, and 19. On day 22, blood was collected for analysis of testosterone, luteinizing hormone ( $\mathrm{LH})$, follicle-stimulating hormone (FSH), alkaline phosphatase (ALP), lactate dehydrogenase (LDH), glutathione peroxidase (GPx), and total antioxidant capacity (TAOC). The testes were also removed and sent for histopathological examination.

Results: The study revealed that the combination of quercetin with sitagliptin produced a significant increase in testosterone and FSH levels with a non-significant increase in LH level. This combination also non-significantly decreased the level of ALP and LDH and restored the GPx level with enhancing TAOC.

Conclusion: The results suggest quercetin/sitagliptin combination as a promising therapeutic modality for attenuation of DOX-induced testicular toxicity in rats, and the main mechanism involved in such effect could be due to the antioxidant and anti-inflammatory properties of both agents.

Keywords: doxorubicin, quercetin, sitagliptin, testicular damage

\section{Introduction}

Cancer chemotherapies have been associated with many adverse effects including infertility, which has emerged as an issue of growing importance issues worldwide. ${ }^{1}$ Doxorubicin (DOX) is one of the anthracycline antibiotics that are widely used for the treatment of various types of malignancies including breast cancer, bladder cancer, and lymphoma. It mainly interacts with DNA by intercalation leading to inhibition of the progression of topoisomerase II enzyme, thus inhibiting DNA replication. ${ }^{2}$ Generation of reactive species is another mechanism of the cytotoxic effect of DOX. Additionally, it produces pronounced DNA damage through histone separation from the active chromatin. ${ }^{3}$ The mechanism that is responsible for the testicular toxicity of DOX is not yet completely clear, but new studies often suggest 
dose-dependent cell death and DNA breaks through affecting the genes involved in cell cycle; ${ }^{4}$ oxidative stress from lipid peroxidation, cellular apoptosis in the spermatocytes and an increased release of pro-inflammatory cytokines as being major causes. These effects may contribute to gonadal damage which may result in male infertility. ${ }^{5}$

Quercetin, a flavanol abundant in many commonly consumed fruits and vegetables, is one of the most potent free radical scavengers. ${ }^{6-8}$ It has been demonstrated to have potent antioxidant and cytoprotective effects in preventing endothelial apoptosis caused by oxidants. ${ }^{9}$ In addition, quercetin protects tissues and organs within the whole body and scale back oxidative injury to fats that reduces cholesterol and protects against artery preventative, cardiovascular, and neurodegenerative diseases. Moreover, it boosts the level of glutathione and prevents cell death through scavenging oxygen radicals. ${ }^{10,11}$

Recently, quercetin has shown to inhibit an enzyme that converts testosterone into a molecule known as testosterone glucuronide, restoring the testosterone level and testicular function. ${ }^{12}$ Sitagliptin is the first dipeptidylpeptidase-4 (DPP4) inhibitor to be used in the management of type 2 diabetes. It is broadly used either as an adjuvant therapy to current management or as monotherapy. ${ }^{13}$ It has been proved to inhibit the expression of inflammatory mediators and suppress NF- $\mathrm{KB}$ activation. ${ }^{14}$ Furthermore, sitagliptin is known to possess antioxidant and anti-inflammatory properties. ${ }^{15,16}$ The combination of DPP4 inhibitor with quercetin has been used recently and showed effectiveness in improving metabolic homeostasis in animal study. ${ }^{17}$ Accordingly, the present study was designed to evaluate the effect of quercetin and/or sitagliptin on testicular damage induced by DOX.

\section{Materials and methods}

Twenty-five male adults sexually mature fully grown Wistar rats, weighing $240 \pm 20 \mathrm{~g}$, were purchased from the Animal house of the University of Sulaimani. The rats were kept in an environmentally controlled breeding room (temperature: $24 \pm 2{ }^{\circ} \mathrm{C}$, humidity: $60 \pm 5 \%, 12 \mathrm{hrs}$ dark-light cycles) for 1 week before the experiment. All animal procedures were approved by the ethical committee of University of Sulaimani in accordance with the institutional Animal Ethics Committee. The rats were fed standard laboratory chow with water ad libitum. All animals were randomly divided into five groups, comprising of five animals each as follows:
Group I: Negative control group; treated with $1 \mathrm{~mL}$ of $0.9 \%$ sodium chloride orally by gavage tube on days 8,10 , $12,15,17$, and 19 from the start of the study.

Group II: DOX-treated group that received DOX I.P. injection $(3 \mathrm{mg} / \mathrm{kg})$ on days $8,10,12,15,17,19$ from the start of the study.

Group III: Treated with quercetin $80 \mathrm{mg} / \mathrm{kg}+$ sitagliptin $10 \mathrm{mg} / \mathrm{kg}$ both given orally by gavage tube daily for 21 days with DOX $3 \mathrm{mg} / \mathrm{kg}$ I.P. injection on days $8,10,12$, $15,17,19$ from the start of the study.

Group IV: Treated with quercetin $80 \mathrm{mg} / \mathrm{kg}$ given orally by gavage tube daily for 21 days with DOX $3 \mathrm{mg} /$ $\mathrm{kg}$ I.P. injection on days $8,10,12,15,17,19$ from the start of the study.

Group V: Treated with sitagliptin $10 \mathrm{mg} / \mathrm{kg}$ given orally by gavage tube daily for 21 days with DOX $3 \mathrm{mg} / \mathrm{kg}$ I.P. injection at days $8,10,12,15,17,19$ from the start of the study.

\section{Assessment of serum biochemical parameters}

At the end of the study on day 22, the rats were fasted overnight and anesthetized with diethyl ether. Blood was collected by cardiac puncture, centrifuged and sera were separated and used for assessment of serum testosterone using ELISA kits purchased from Microlisa AMGENIX Int, Inc. USA according to the manufacturer's instructions. In addition, serum luteinizing hormone (LH) and folliclestimulating hormone (FSH) were measured using ELISA kits obtained from DRG Diagnostics, Marburg, Germany according to the manufacturer's protocol.

\section{Assessment of alkaline phosphatase (ALP) and lactate dehydrogenase (LDH)}

The activities of ALP and LDH were measured using kits supplied by Sigma Aldrich Co. based on the instructions of the manufacturer.

\section{Assessment of serum oxidative stress markers}

Serum glutathione peroxidase (GPx) activity was assessed spectrophotometrically using the method of Wendel ${ }^{18}$ through the glutathione/NADPH/glutathione reductase system, by dismutation of $\mathrm{H}_{2} \mathrm{O}_{2}$ at $340 \mathrm{~nm}$. Serum total antioxidant capacity (TAOC) was measured using assay kits purchased from Elabscience, USA, according to the manufacturer's protocol. 


\section{Histological studies and preparation Histological preparation}

The testis were removed and cleared from blood and adhering connective tissue, then sliced into small sections of about $0.5-1 \mathrm{~cm}$ thick and fixed in $10 \%$ neutral-buffered formalin (100 mL formalin (40\%), $4 \mathrm{~g}$ sodium phosphate monobasic, $6.5 \mathrm{~g}$ sodium phosphate dibasic and $900 \mathrm{~mL} \mathrm{D.W}$ ), for at least $48 \mathrm{hrs}$. The fixed samples were placed in plastic cassettes and dehydrated. The tissues were embedded in paraffin wax, and the blocks were trimmed and sectioned to $5 \mu \mathrm{m}$ using a semi-automated microtome. Then, the tissue sections were mounted on glass slides using a hot plate. Later, the tissue sections were deparaffinized by two changes of xylene for 5 mins each and rehydrated by three changes of different graded ethanol dilution $(100 \%, 90 \%$, and $70 \%)$ for $5 \mathrm{mins}$ each, respectively. Afterward, the sections were stained with Harris's hematoxylin and eosin method. Finally, tissue sections were mounted with glassy cover slips using mounting medium Distrene-Plasticizer Xylene (DPX), and examined using light microscope image analyzer under high power $100 \mathrm{X}$ and low power of $40 \mathrm{X}$ magnifications.

\section{Histopathological evaluation}

Morphometric measurement of histological sections from testis of each animal was analyzed and measured in $\mu \mathrm{m}$ and statistically expressed as mean percentage. Tissue slides were examined under the light microscope (Olympus BX51, Japan) with the aid of image analyzer (AmScope 3.7, for digital camera, 2017) to evaluate damage severity in spermatogenic cells. A total of 10 randomly chosen different fields were selected from each section to evaluate the damage in the seminiferous tubules and the germinal cells under high power (100X) magnification. The average of degenerative and apoptotic cell counts was measured in summation of 10 fields. The following morphometric scores were considered for the semiquantitative evaluation of the sections (score 0, score 1, score 2, score 3 and score 4). Finally, lesion severity was graded according to the percentage of degenerative and apoptotic germinal cells as follows; 0-10\%: no lesion; 10-25\%: mild; 25-50\%: moderate; 50-75\%: severe; $75-$ 100\%: critical.

\section{Statistical analysis}

The statistical analysis was performed using GraphPad Prism 7. The values of the measured parameters were expressed as mean \pm standard deviation (S.D.). For the comparisons between different groups, one-way analysis of variance
(ANOVA), followed by Bonferroni multiple comparison test was used. The results were considered statistically significant when the $p$-value was less than 0.05 .

\section{Results}

\section{Effect of quercetin and/or sitagliptin on serum testosterone, $\mathrm{LH}$ and FSH in DOX- treated rats}

DOX induced a significant decrease $(P$-value $<0.0001)$ in the level of serum testosterone and LH $(61.14 \pm 5.251$ vs $225.4 \pm 6.022),(0.074 \pm 0.005$ vs $0.118 \pm 0.0037)$ respectively, and a significant decrease $(P$-value $=0.0039)$ in FSH level $(0.076 \pm 0.006$ vs $0.1 \pm 0)$ compared to the negative control.

The use of the quercetin/sitagliptin combination induced a significant increase $(P$-value $<0.0001)$ in the levels of testosterone compared to the DOX group (217.4 \pm 1.5 vs $61.14 \pm 5.251)$, and this level was comparable $(P$-value $=0.234)$ to that of negative control $(217.4 \pm 1.5 \mathrm{vs}$ $225.4 \pm 6.022)$. Non-significant increase in testosterone level was observed in groups treated with either quercetin or sitagliptin with DOX compared to DOX group (Figure 1). Slight non-significant elevation in the level of LH was seen in group treated with quercetin and quercetin/sitagliptin combination compared to DOX-treated group (Figure 2). Regarding the effect on $\mathrm{FSH}$, this combination produced a significant $(P$-value $<0.05)$ increase $(0.096 \pm 0.005$ vs 0.076 $\pm 0.013)$. No significant change seen in the other groups compared to rats treated with DOX (Figure 3).

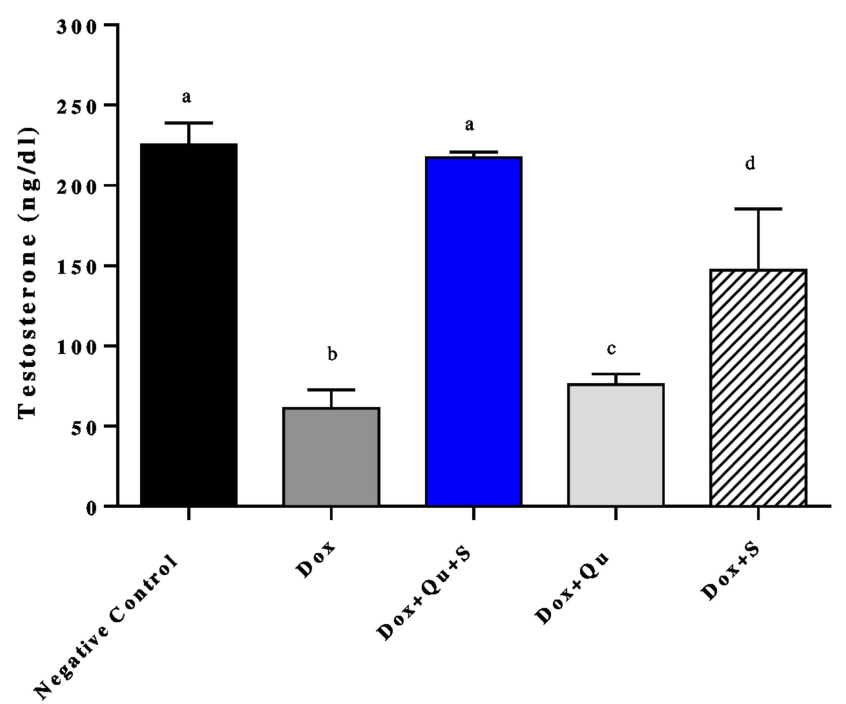

Figure I Effect of quercetin and/or sitagliptin on serum testosterone level. Note: Values of non-identical letters (a, b, c, d) are significantly different among groups $(P<0.001), n=5$ in each group. 


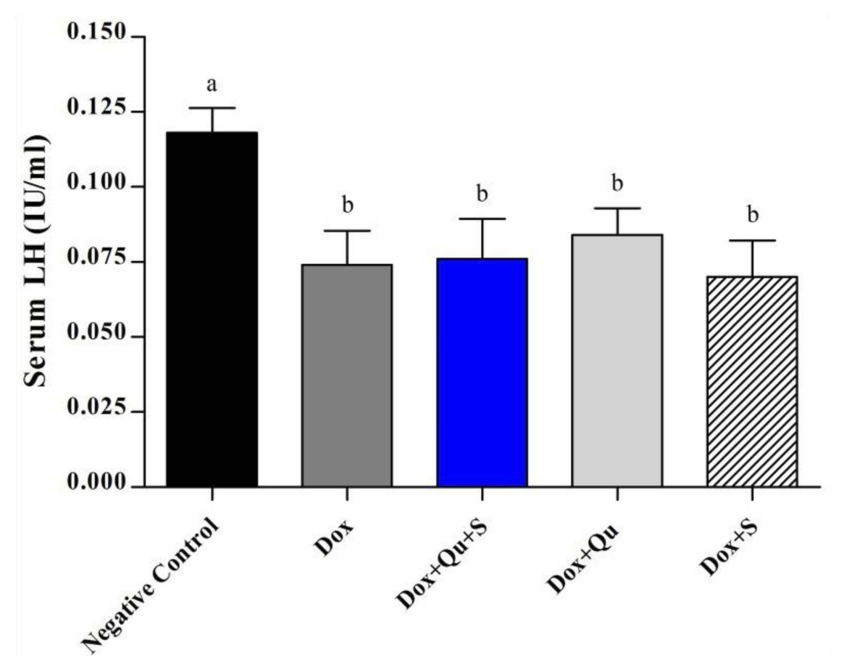

Figure 2 Effect of quercetin and/or sitagliptin on serum LH level.

Note: Values with non-identical letters $(\mathrm{a}, \mathrm{b})$ are significantly different among groups $(P<0.05), n=5$ in each group.

Abbreviation: $\mathrm{LH}$, luteinizing hormone.

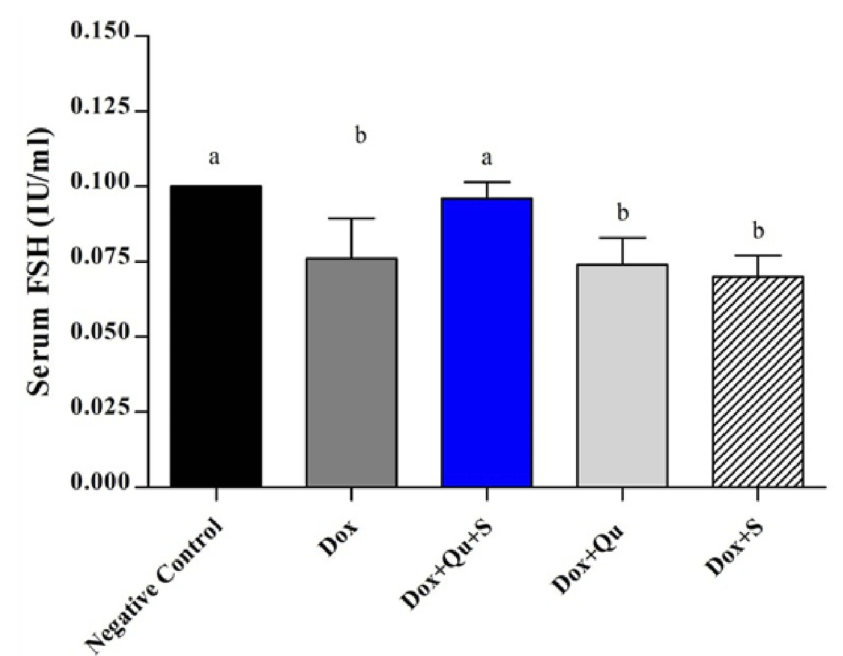

Figure 3 Effect of quercetin and/or sitagliptin on serum FSH level.

Note: Values with non-identical letters $(a, b)$ are significantly different among groups $(P<0.05), n=5$ in each group.

Abbreviation: $\mathrm{FSH}$, follicle-stimulating hormone.

\section{Effect of quercetin and/or sitagliptin on} ALP and LDH in DOX-treated rats

DOX-induced a significant increase $(P$-value $<0.01)$ in serum ALP compared to the control group $(123.4 \pm 18.83$ vs $36.86 \pm 1.94)$. The use of the quercetin/sitagliptin combination induced a non-significant decrease $(P$-value $=0.055)$ in the levels of ALP compared to rats treated with DOX alone and compared to the use of each of these drugs alone (Figure 4). In addition, the use of DOX produced a significant increase $(P$-value $<0.01)$ in the level of LDH compared to the control group ( $222.4 \pm 32.58$ vs $103 \pm 11.78)$, and the use of the

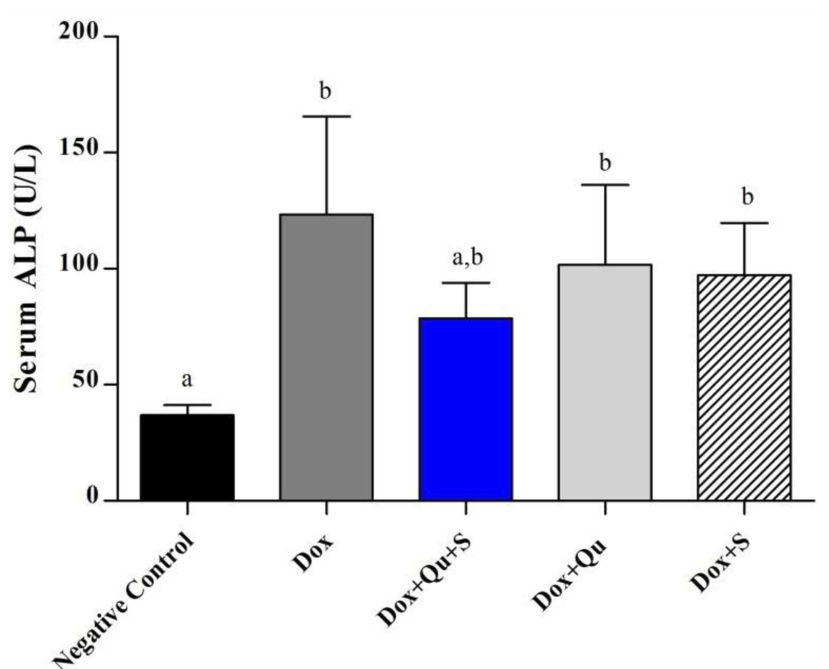

Figure 4 Effect of quercetin and/or sitagliptin on serum ALP level. Note: Values with non-identical letters $(a, b)$ are significantly different among groups $(P<0.05), n=5$ in each group.

Abbreviation: ALP, alkaline phosphatase.

quercetin/sitagliptin combination and sitagliptin alone induced a decrease in the levels of LDH almost comparable with that produced by the control group (Figure 5).

\section{Effect of quercetin and/or sitagliptin on oxidative stress markers in DOX-treated rats}

DOX induced a non-significant decrease $(P$-value $=0.058)$ in the level of GPx compared to the negative control group $(6227 \pm 569$ vs $7518 \pm 133)$. The use of quercetin or sitagliptin

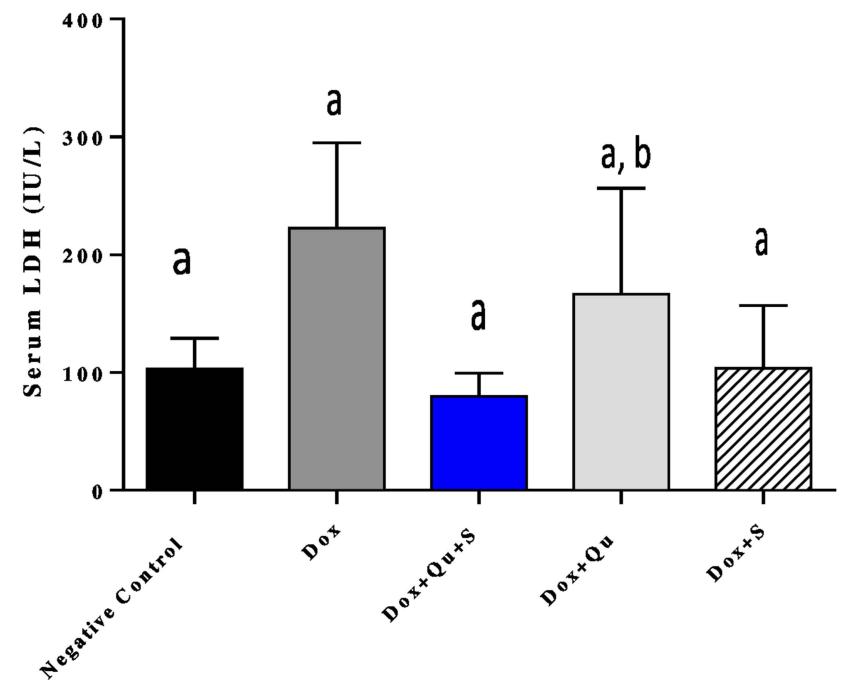

Figure 5 Effect of quercetin and/or sitagliptin on serum LDH level.

Note: Values with non-identical letters $(a, b)$ are significantly different among groups $(P<0.05), n=5$ in each group. 
alone almost restored the level of GPx $(7501 \pm 129$ vs 7518 $\pm 133)$, (7510 \pm 133 vs $7518 \pm 133$ ) (Figure 6). Furthermore, DOX significantly decreased $(P$-value $<0.0001)$ the level of TAOC compared to the control group $(0.018 \pm 0.001$ vs $0.108 \pm 0.003)$. The use of quercetin alone and with sitagliptin produced an effect comparable to the control group ( $0.11 \pm 0.004$ vs $0.108 \pm 0.003),(0.13 \pm 0.008$ vs $0.108 \pm 0.003)$, respectively (Figure 7).

\section{Histopathological results}

Table 1 demonstrates the morphometric semiquantitative evaluation of testis histological sections to assess the lesion

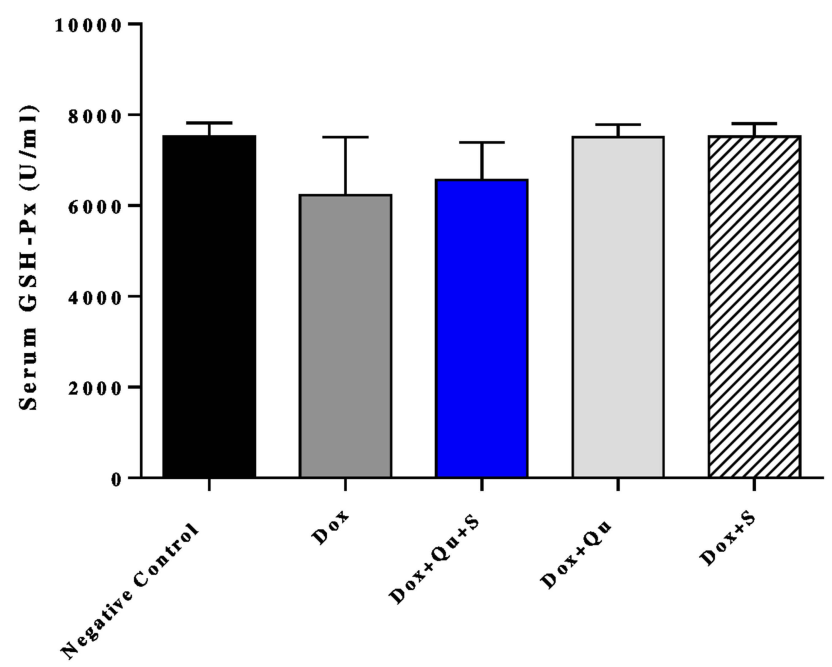

Figure 6 Effect of quercetin and/or sitagliptin on serum glutathione peroxidase level. $n=5$ in each group.

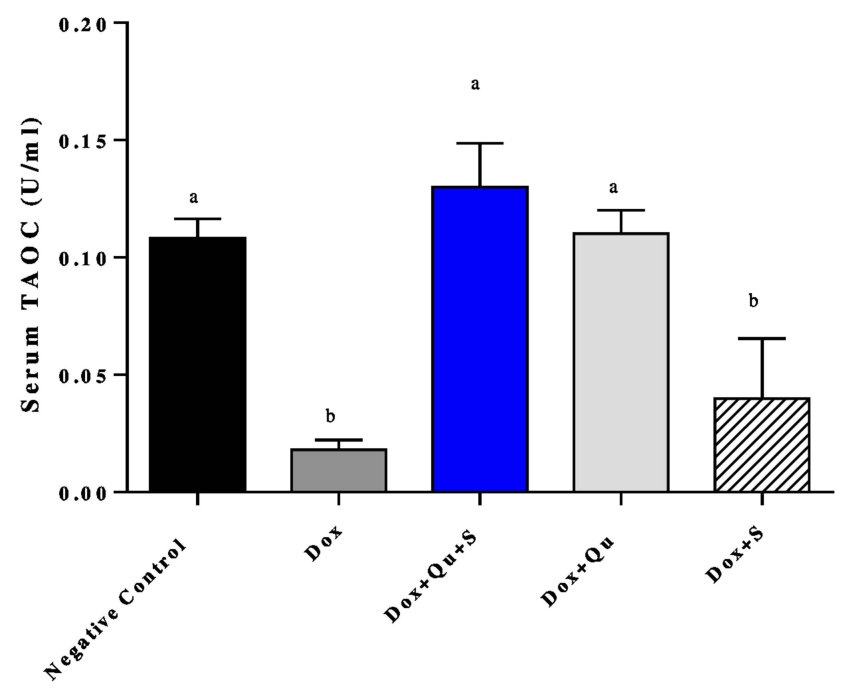

Figure 7 Effect of quercetin and/or sitagliptin on serum TAOC level.

Note: Values of non-identical letters $(a, b)$ are significantly different among groups $(P<0.001), n=5$ in each group.

Abbreviation: TAOC, total antioxidant capacity. scoring and grading indexes, which shows significant $P<0.05$ reduction in the percentage of degenerative and apoptotic germinative sperm cells in (Dox $+\mathrm{Qu}+\mathrm{S}$ group) in comparison with Dox group. Moreover, the morphometric evaluation of damage severity also was significant in groups IV and $\mathrm{V}$ in comparison with groups II (Dox group).

In addition, Figures 8 and 9 clarify the overall morphological changes in different treatment groups. Initially, Dox administration induces a significant reduction in spermatogenesis with obvious decrease in spermatogenic cells in comparison to control group. This is associated with severe degenerative changes in epithelial germinative cell layers. On the other hand, (Dox $+\mathrm{Qu}+\mathrm{S}$ group) reveals significant germinal regenerative modifications together with complete restoration of germinative sperm cells in comparison with group B (Dox group). Furthermore, (Dox $+\mathrm{S}$ group), shows regeneration in spermatogenic lining epithelium of some seminiferous tubules. However, some other spermatogenic cells show characteristic degenerative changes, evident by the presence of cellular debris. Concerning (Dox $+\mathrm{Qu}$ group), the histopathological results indicate significant regeneration in most seminiferous tubular germinal epithelium in comparison with the Dox group evident by uniformly arranged spermatogenic cells. Although, some germinative sperm cells still display distinguish degenerative shift expressed by the presence of cellular debris within the seminiferous tubular lumen.

\section{Discussion}

The main aim of this study was to investigate the possible protective effects of quercetin and the antidiabetic drug sitagliptin against the development of DOX-induced testicular toxicity in rats, since recently this combination proved to have better effects when used in diabetic rats through improving glycemic and antioxidant status. ${ }^{19}$ In this study, DOX affected testicular function compared with the control; it appeared to significantly decrease the level of testosterone, FSH and LH. This finding was in tune with other studies that reported DOX induced a significant decline in serum testosterone, LH and FSH which in turn will be reflected on spermatogenesis as well as on the structural morphology of the seminiferous tubules. ${ }^{20,21}$ The use of the quercetin and/or sitagliptin produced a significant increase in the level of testosterone and FSH compared with the group treated with DOX alone. Interestingly, the combination of both quercetin and sitagliptin resulted in a comparable level of testosterone and FSH to that of the control group. This combination also 
Table I Histological quantitative evaluation of damaged severity in spermatogenic cells

\begin{tabular}{|l|l|l|l|l|}
\hline Experimental groups N=5 & $\begin{array}{l}\text { Degenerative cells (\%) } \\
\text { M } \pm \text { SD** }\end{array}$ & Apoptotic cells (\%) M \pm SD** & Lesion scoring (0-4) & Lesion grading \\
\hline CN (A)† & $1.4 \%(0-10)^{1}, \#$ & $0.9 \%(0-10)^{1}$ & 0 & No lesion \\
Dox (B) & $84.1 \%(75-100)^{5}$ & $86.2 \%(75-100)^{5}$ & 4 & Critical \\
Dox+Qu +S (C) & $43.3 \%(25-50)^{2}$ & $41.7 \%(25-50)^{2}$ & 2 & Moderate \\
Dox+S (D) & $48.2 \%(25-50)^{3}$ & $46.8 \%(25-50)^{3}$ & 2 & Moderate \\
Dox+Qu (E) & $58.7 \%(50-75)^{4}$ & $56.1 \%(50-75)^{4}$ & 3 & Severe \\
\hline
\end{tabular}

Notes: **Each value represents mean \pm SDM $(n=5)$. \#Statistical comparison among groups: Mean values with different numbers within the same column have significant differences at $(P<0.05)$. $† A$ : Control negative; $B$ : doxorubicin group; $C$ : doxorubicin, quercetin and sitagliptin group; $D$ : doxorubicin and sitagliptin group; E: doxorubicin and quercetin group.

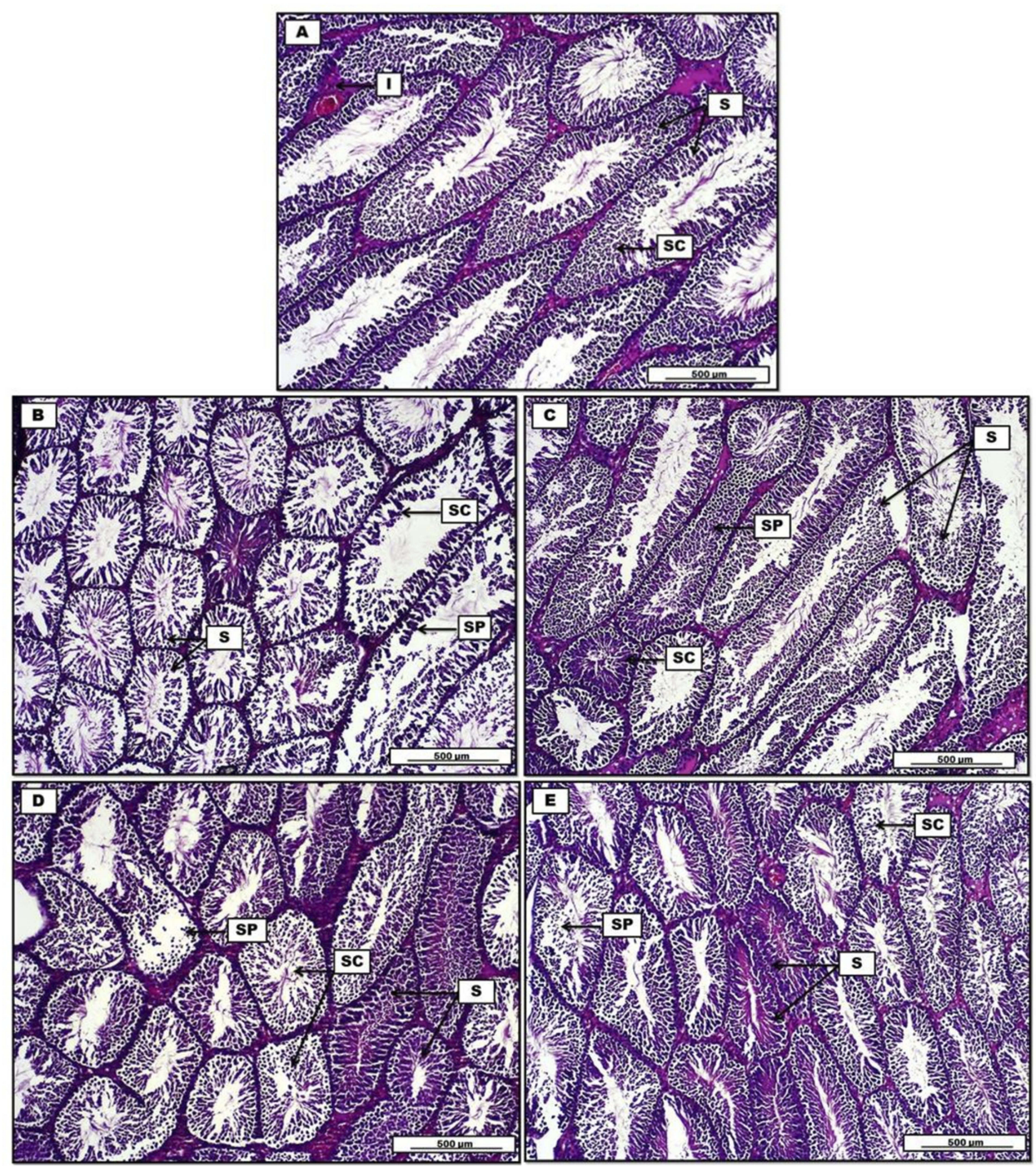

Figure 8 Photomicrograph of testis from groups; (A) control group, display consistent numbers of seminiferous tubules (S), separated by interstitial connective tissue (I) lined by uniformly arranged spermatogenic cells (SC). (B) Doxorubicin group show a significant reduction in spermatogenesis (SC), decrease in seminiferous tubules spermatogenic cells (S), together with severe degenerative changes in germinative sperm cell layers (SP). (C) Doxorubicin, quercetin and sitagliptin group reveal significant germinal regeneration in the spermatogenic cells (SC). Repopulation in the germinative cells of spermatogenesis (SP). Some tubules show degenerative changes in lining germinal epithelium (S). (D) Doxorubicin and sitagliptin group show regenerative changes in some seminiferous tubules (S), spermatogenic cells (SC) show typical degenerative-atrophy changes, and germinative spermatogenesis epithelium debris within the testicular tubules (SP). (E) Doxorubicin and quercetin group display significant regeneration in seminiferous tubular germinal epithelium (S), marked cellular debris within the tubular lumen (SP), and degenerative changes in spermatogenic cells (SC). H\&E. Scale bars: $500 \mu \mathrm{m}$. 


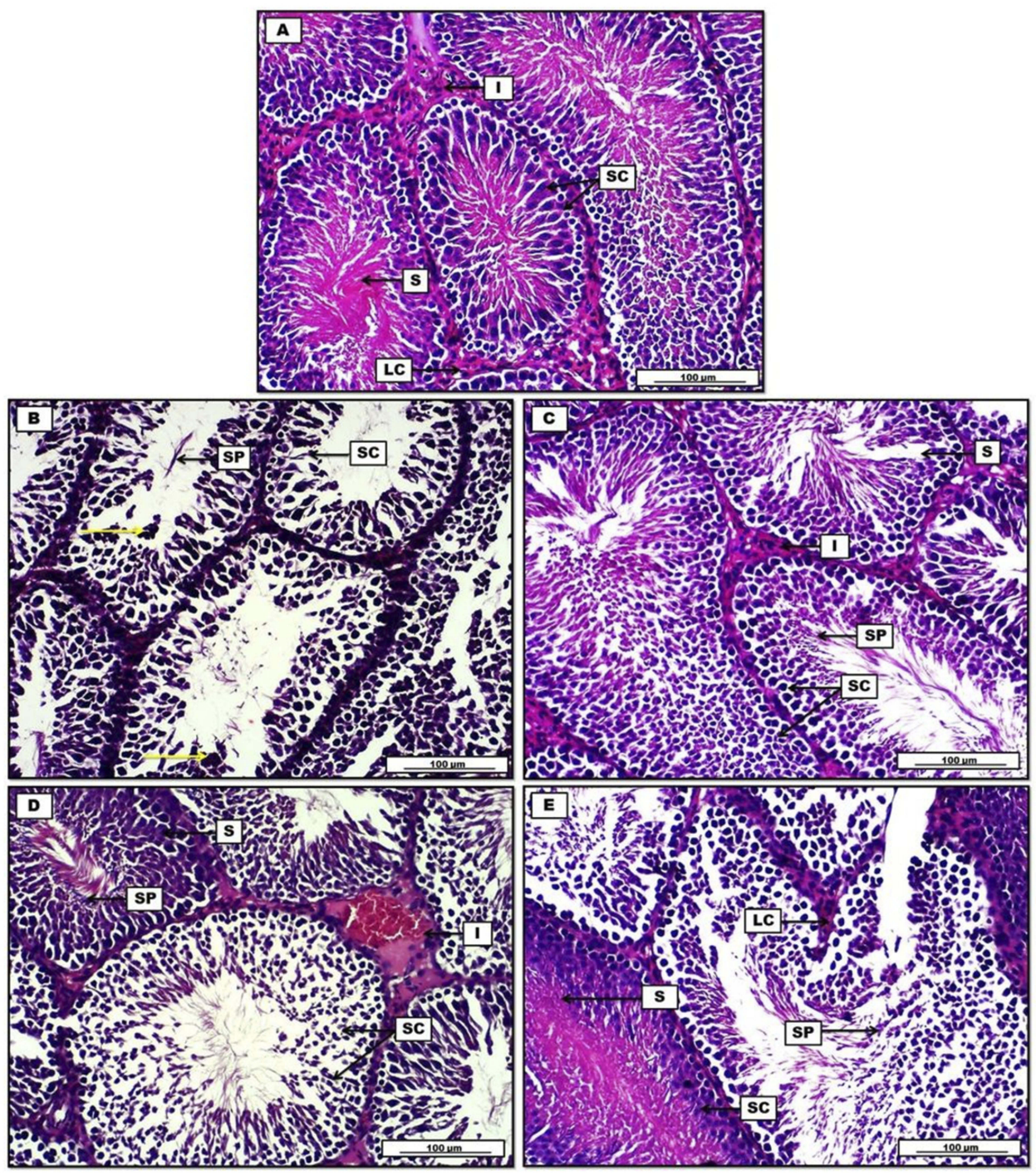

Figure 9 Photomicrograph of testis from groups; (A) control group shows normal morphogenic arrangement of spermatic cells (SC) and seminiferous tubules (S) which enclose a dense pinkish appearance of spermatozoa tails. Leydig cells (LC) with prominent acidophilic cytoplasm in the interstitial connective tissue (I). (B) Doxorubicin group demonstrates germinal aplasia with degeneration in spermatogenic cells (SC), sloughing of germ cells evident by dead sperm cells fragments (SP), presence of hyperchromatic apoptotic debris (yellow arrows). (C) Doxorubicin, quercetin and sitagliptin group display significant morphogenic improvements in the spermatogenic cells (SC), spermatic repopulation and regeneration (SP) can be seen within seminiferous tubules (S), interstitial tissue (I) show distinctive distribution. (D) Doxorubicin and sitagliptin group show regeneration of germinal epithelium (SP) of some seminiferous tubules (S), other spermatogenic cells show degenerative changes, evident by cellular debris (SC). Blood vessels congestion in the interstitium (I). (E) Doxorubicin and quercetin group show regeneration of germinative spermatogenic cells (SC) within the seminiferous tubules (S), presence of cellular debris in the lumen (SP). H\&E. Scale bars: $100 \mu \mathrm{m}$.

non-significantly increased the level of LH. Another indicator of testicular toxicity was manifested by the elevation in serum level of ALP and LDH produced by DOX and confirmed by histopathological examination. The activity of ALP on the endothelial cell surface is responsible, in part, for the conversion of adenosine nucleotides to adenosine a potent vasodilator and anti-inflammatory mediator that can protect tissues from the damage that results from injury. ${ }^{22}$ On the other hand, $\mathrm{LDH}$ is important for spermatogenesis and testicular metabolism. ${ }^{23}$ Disturbance of the levels of these enzymes may contribute to testicular damage. The combination of quercetin with sitagliptin almost normalized ALP and LDH levels, which could be attributed to the antioxidant and anti-inflammatory properties of both quercetin and sitagliptin. Sitagliptin has previously been proven to attenuate the toxic effects of DOX on androgen synthesis. The proposed mechanism could be the ability of DPP-4 to counteract mitochondrial impairment, enhance energy production, and inhibition of DNA damage induced by $\mathrm{DOX}^{24}$ Additionally, it has been found that treatment with DPP-4 inhibitors might interfere with the sperm's forward motility. Other studies suggest 
the involvement of DPP-4 enzyme in the control of sperm movement. $^{21}$

With regard to the effect of DOX on the oxidative status in this study; DOX produced a significant decrease in the level of GSH peroxidase and a significant decrease in TAOC level. It has been reported that oxidative stress plays a crucial role in the testicular damage induced by DOX. The main mechanism of DOX involvement in oxidative damage is attributed to its ability to interact with cellular macromolecules ${ }^{20}$ and this was the reason behind choosing DOX to target rapidly dividing cells, disrupting cell growth, mitotic activity, and differentiation. Furthermore, DOX is capable of elevating the ratio of superoxide dismutase to GPx and/or catalase which eventually result in increased $\mathrm{H}_{2} \mathrm{O}_{2}$ accumulation ${ }^{25}$ that initiate oxidative DNA damage. ${ }^{26,27}$ The high concentration of $\mathrm{H}_{2} \mathrm{O}_{2}$ may result in the production of one of the most dangerous free radical, hydroxyl radical $(\mathrm{OH} \cdot)$, through Fenton reaction and because of the high reactivity and very short half-life; it rapidly initiates lipid peroxidation and DNA cross-linking. ${ }^{25}$ Sitagliptin in the present study was able to increase the activity of the antioxidant enzymes and enhance the antioxidant capacity. This could be attributed to decreasing lipid peroxidation. ${ }^{28}$ This finding was in line with Bao et $\mathrm{al}^{29}$ and Steven et $\mathrm{al}^{30}$ who attributed the antioxidant effects of DPP-4 inhibitors to elevated GLP-1 level since this effect could be blocked by a GLP-1 receptor antagonist. Moreover, GLP-1 was proven to activate AMP-activated protein kinase which in turn enhances the activity of the antioxidant enzymes leading to significant amelioration of oxidative stress. Our finding showed that quercetin also was able to restore the GSH peroxidase level and boost the antioxidant capacity. The natural flavonoid quercetin is well known for its cytoprotective activity, mainly through decreasing lipid peroxidation and boosting the antioxidant system. ${ }^{31,32}$ In the current study, remarkable improvement in the histopathology was noticed with the use of quercetin and/or sitagliptin, which could be mainly attributed to the fact that DPP-4 inhibitors have potent antiapoptotic properties, possibly through suppression of mRNA expression of the proapoptotic proteins ${ }^{21}$ and the protective effects of quercetin in testicular tissue. Furthermore, the protective effect of quercetin in the testicular tissue, kidney, and various other tissues has been reported in many studies. ${ }^{31,32}$

\section{Conclusion}

The results of the current study suggest quercetin/sitagliptin combination as a promising therapeutic modality for attenuation of DOX-induced testicular toxicity in rats, and the main mechanism involves in such effect could be due to the antioxidant and anti-inflammatory properties of both agent. Further study is warranted to support this finding.

\section{Acknowledgment}

The authors appreciate the College of Pharmacy, University of Sulaimani for its support and for providing facilities to this project.

\section{Disclosure}

The authors report no conflicts of interest in this work.

\section{References}

1. Hee Lee S, Ho Shin C. Reduced male fertility in childhood cancer survivors. Ann Pediatr Endocrinol Metab. 2013;18:168-172. doi:10.6065/apem

2. Adwas AA, Elkhoely AA, Kabel AM, Abdel-Rahman MN, Eissa AA. Anti-cancer and cardioprotective effects of indol-3-carbinol in doxorubicin-treated mice. J Infect Chemother. 2016;22(1):36-43. doi:10.1016/j.jiac.2015.10.001

3. Pang B, Qiao X, Janssen L, et al. Drug-induced histone eviction from open chromatin contributes to the chemotherapeutic effects of doxorubicin. Nat Commun. 2013;4(1):1908. doi:10.1038/ncomms2921

4. Beaud H, van Pelt A, Delbes G. Doxorubicin and vincristine affect undifferentiated rat spermatogonia. Reproduction. 2017;153(6):725735. doi:10.1530/REP-17-0005

5. Türedi S, Yuluğ E, Alver A, Kutlu Ö, Kahraman C. Effects of resveratrol on doxorubicin induced testicular damage in rats. Exp Toxicol Pathol. 2015;67(3):229-235. doi:10.1016/j.etp.2014.12.002

6. Zhang M, Swarts SG, Yin L, et al. Antioxidant properties of quercetin. Adv ExpMed Biol. 2011;701:283-289. Available from: http:// www.ncbi.nlm.nih.gov/pubmed/21445799

7. McAnulty LS, Miller LE, Hosick PA, Utter AC, Quindry JC, McAnulty SR. Effect of resveratrol and quercetin supplementation on redox status and inflammation after exercise. Appl Physiol Nutr Metab. 2013;38(7):760-765. doi:10.1139/apnm-2012-0455

8. Gao C, Chen X, Li J, et al. Myocardial mitochondrial oxidative stress and dysfunction in intense exercise: regulatory effects of quercetin. Eur J Appl Physiol. 2014;114(4):695-705. doi:10.1007/s00421-014-2985-8

9. Choi Y, Kang J, Han J, et al. Biochemical and molecular actions of nutrients polyphenolic flavonoids differ in their antiapoptotic efficacy in hydrogen peroxide - treated human vascular endothelial cells. $J$ Nutr. 2003;133:985-991. doi:10.1093/jn/133.8.2622

10. D'Andrea G. Quercetin: a flavonol with multifaceted therapeutic applications? Fitoterapia. 2015;106:256-271. doi:10.1016/j.fitote. 2015.09.018

11. Inal ME, Akgün A, Kahraman A. Radioprotective effects of exogenous glutathione against whole-body gamma-ray irradiation: age- and gender-related changes in malodialdehyde levels, superoxide dismutase and catalase activities in rat liver. Methods Find Exp Clin Pharmacol. 2005;24(4):209. doi:10.1358/mf.2002.24.4.678452

12. Bharti S, Misro MM, Rai U. Quercetin supplementation restores testicular function and augments germ cell survival in the estrogenized rats. Mol Cell Endocrinol. 2014;383(1-2):10-20. doi:10.1016/j. mce.2013.11.021

13. Eligar VS, Bain SC. A review of sitagliptin with special emphasis on its use in moderate to severe renal impairment. Drug Des Devel Ther. 2013;7:893-903.

14. Chien-Hung L, Chung Ching L. Sitagliptin attenuate inflammatory responses in lipopolysaccharide stimulated cardiomyocytes via nuclear factor $\kappa \mathrm{B}$ pathway inhibition. Exp Ther Med. 2016;11:26092615. doi:10.3892/etm.2016.3255 
15. Vaghasiya J, Sheth N, Bhalodia Y, Manek R. Sitagliptin protects renal ischemia reperfusion induced renal damage in diabetes. Regul Pept. 2011;166(1-3):48-54. doi:10.1016/j.regpep.2010.08.007

16. Makdissi A, Ghanim H, Vora M, et al. Sitagliptin exerts an antinflammatory action. J Clin Endocrinol Metab. 2012;97(9):33333341. doi:10.1210/jc.2012-1544

17. Henrique de Miranda PA, Christine Duarte Lacerda K, Morais Araújo C, Mario Barichello J, Geraldo Lima W, Caldeira Costa D. Oral formulation of DPP-4 inhibitor plus Quercetin improves metabolic homeostasis in type 1 diabetic rats. Sci Rep. 2018;8:15310. doi:10.1038/s41598-018-33727-x

18. Wendel A. Glutathione peroxidase. Methods Enzymol. 1981;77:325333.

19. Eitah HE, Maklad YA, Abdelkader NF, Gamal El Din AA, Badawi MA, Kenawy SA. Modulating impacts of quercetin/sitagliptin combination on streptozotocin-induced diabetes mellitus in rats. Toxicol Appl Pharmacol. 2019;365:30-40. doi:10.1016/j.taap.2018.12.011

20. Abdella E, Ahmed R. Suppression of doxorubicin apoptotic, histopathologic, mutagenic and oxidative stress effects in male mice bone marrow and testis tissues by aqueous rosemary leaves extract. Iran J Cancer Prev. 2009;1:35-49.

21. Kabel AM. Zinc/alogliptin combination attenuates testicular toxicity induced by doxorubicin in rats: role of oxidative stress, apoptosis and TGF- $\beta 1 / N F-\kappa B$ signaling. Biomed Pharmacother. 2018;97:439-449. doi:10.1016/j.biopha.2017.10.144

22. Swamy AV, Gulliaya S, Thippeswamy A, Koti BC, Manjula DV. Cardioprotective effect of curcumin against doxorubicin-induced myocardial toxicity in albino rats. Indian $J$ Pharmacol. 2012;44 (1):73-77. doi:10.4103/0253-7613.91871

23. Na F, Zhang J, Liang C, Ma J, Zhou B, Wang J. Changes in testis protein and metabolic enzyme activities in rats induced changes in testis protein and metabolic enzyme activities in rats induced by sodium fluoride and sulfur dioxide. Res Report Fluoride. 2006;39 (3):179-184
24. Zhang X, Zhang Z, Zhao Y, et al. Alogliptin, a dipeptidyl peptidase-4 inhibitor, alleviates atrial remodeling and improves mitochondrial function and biogenesis in diabetic rabbits. $J$ Am Heart Assoc. 2017;6:e005945. doi:10.1161/JAHA.117.005945

25. Mishra. Doxorubicin mediated oxidative stress induced degeneration of testicular tissues causes male sterility in rats. J Cell Tissue Res. 2007;7(1):861-866.

26. Mizutani H, Tada-Oikawa S, Hiraku Y, Kojima M, Kawanishi S. Mechanism of apoptosis induced by doxorubicin through the generation of hydrogen peroxide. Life Sci. 2005;76(13):1439-1453. doi:10.1016/j.lfs.2004.12.010

27. Hozayen WG. Effect of hesperidin and rutin on doxorubicin induced testicular toxicity in male rats. Int J Food Nutr Sci. 2012;1:31-42.

28. Nuransoy A, Beytur A, Polat A, Samdanci E, Sagir M, Parlakpinar H. Renal Failure Protective effect of sitagliptin against renal ischemia reperfusion injury in rats Protective effect of sitagliptin against renal ischemia reperfusion injury in rats. Ren Fail. 2015;37(4):687-693. doi:10.3109/0886022X.2015.1010991

29. Bao W, Morimoto K, Hasegawa T, et al. Orally administered dipeptidyl peptidase-4 inhibitor (alogliptin) prevents abdominal aortic aneurysm formation through an antioxidant effect in rats. $J$ Vasc Surg. 2014;59(4):1098-1108. doi:10.1016/j.jvs.2013.04.048

30. Steven S, Münzel T, Daiber A. Exploiting the pleiotropic antioxidant effects of established drugs in cardiovascular disease. Int $J$ Mol Sci. 2015;16:18185-18223 p. doi:10.3390/ijms160818185

31. Farombi EO, Adedara IA, Akinrinde SA, Ojo OO, Eboh AS. Protective effects of kolaviron and quercetin on cadmium-induced testicular damage and endocrine pathology in rats. Andrologia. 2012;44(4):273-284. doi:10.1111/j.1439-0272.2012.01279.x

32. Prabu SM, Shagirtha K, Renugadevi J. Amelioration of cadmiuminduced oxidative stress, impairment in lipids and plasma lipoproteins by the combined treatment with quercetin and $\alpha$-tocopherol in rats. J Food Sci. 2010;75(7):T132-40. doi:10.1111/j.1750-3841.2010. 01757.x

\section{Publish your work in this journal}

Drug Design, Development and Therapy is an international, peerreviewed open-access journal that spans the spectrum of drug design and development through to clinical applications. Clinical outcomes, patient safety, and programs for the development and effective, safe, and sustained use of medicines are a feature of the journal, which has also been accepted for indexing on PubMed Central. The manuscript management system is completely online and includes a very quick and fair peer-review system, which is all easy to use. Visit http://www. dovepress.com/testimonials.php to read real quotes from published authors. 